\title{
Lymphangioma of the Spleen-A Rare Tumor Rarely seen in an Adult: A Case Report and a Comprehensive Literature Review
}

\author{
Basil George Verghese, Sanjana Kalvehalli Kashinath, R Ravi Kanth
}

\begin{abstract}
Lymphangioma of the spleen, a cystic, benign and slow growing tumor, is rarely seen in children and in adults and usually found only incidentally. We would like to report a case of a splenic lymphangioma in a 33-year-old female that presented to our hospital. To our knowledge this is the first case of its kind being reported from the Indian subcontinent in over 35 years. The previous case was reported in 1974 by Devi et al. In addition to this, our case is also unique because of the age of the patient and the size of the lymphangioma being one of the largest reported so far. This case report will be followed with a detailed literature review of splenic lymphangioma and its management.
\end{abstract}

Abbreviations: $\mathrm{Hb}$ : Hemoglobin; ESR : E rythrocyte sedimentation rate; APTT: Activated partial thromboplastin time; GI: Gastrointestinal; CT: Computerized tomography; MR I: Magnetic resonance imaging.

Keywords: Lymphangioma, Lymphangioma of the spleen, Benign tumor of the spleen, Spleen.

How to citethis article: Verghese BG, Kashinath SK, Ravi Kanth $R$. Lymphangioma of the Spleen-A Rare Tumor Rarely seen in an Adult: A Case Report and a Comprehensive Literature Review. Euroasian J Hepato-Gastroenterol 2013;3(1):64-69.

\section{Source of support $\mathrm{Nil}$}

Conflict of interest: None

\section{INTRODUCTION}

Lymphangioma of the spleen is cystic, benign and slow growing tumor that is rarely seen in children and even rarer in adults and is usually found only incidentally. ${ }^{1}$ To our knowledge this is the first case of its kind being reported from the Indian subcontinent in over 35 years. The previous case was reported in 1974 by Devi et al. ${ }^{2}$ Lymphangiomas were first described by Rodenber in $1828^{3}$ and the first case of lymphangioma of spleen was reported by F rink in $1885 .{ }^{4}$ Primary benign tumors of the spleen account for only $0.007 \%$ of all operations and autopsies. ${ }^{2}$ Since, 1939 to 1990 around 180 cases of splenic lymphangioma have been reported. ${ }^{5}$ The majority of those cases was cystic lymphangioma and included cases which developed as a part of systemic lymphangiomatosis. ${ }^{3,6}$ A nother feature of the same disease is isolated splenic lymphangiomatosis and is a much rarer form; from 1990 to 2010 , only nine cases have been described in the literature. ${ }^{7-15}$ Splenic lymphangioma with a solid gross appearance is rare, and only a few cases have been reported so far. ${ }^{16-20}$
The series of Goh published in 2005 reported 14 intraabdominal lymphangiomas over a period of 15 years of which one patient presented with a splenic lymphangioma. ${ }^{21}$ In another study conducted in 2006 by A llen et al, reported six patients with intra-abdominal lymphangiomas over a period of 18 years, none of which was a splenic lymphangioma. ${ }^{22}$

\section{CASE REPORT}

A 33 years old, unmarried female patient reported to the surgical department with a history of pain in abdomen and early satiety since 1 month. The pain was more in the epigastric region with occasional radiation to the left upper quadrant. She described the pain as a burning type of pain which aggravated with intake of food. She also complained of fullness of the abdomen and early satiety on taking food. She had no other complaints. She reported having similar complaints intermittently in the past which used to resolve with over the counter antacids. She had no history of weight loss. She had no previous history of trauma to the abdomen or any intra-abdominal infection.

Physical examination revealed no acute distress with stable vital signs. General examination revealed no pallor, no icterus and no lymphadenopathy. On abdominal examination, spleen was palpable till the umbilicus. It was firm and nontender. Rest of the systemic examination was normal.

Her blood investigations were reported as follows; hemoglobulin: $11 \mathrm{gm} / \mathrm{dl}$, white blood cell count: 6,100 cells/ $\mathrm{mm}^{3}$, differential count: neutrophils $60 \%$, lymphocytes $36 \%$, eosinophils $4 \%$, erythrocyte sedimentation rate (ESR): $16 \mathrm{~mm} / \mathrm{hr}$, platelet count: 2.57 lakhs/dl, bleeding time: 2 minutes, Clotting time: 8 minutes, prothrombin time: 16 seconds (control: 14 seconds), international normalized ratio (INR): 1.11, activated partial thromboplastin time (APTT): 30 seconds (control: 28 seconds), random blood sugar: $91 \mathrm{mg} / \mathrm{dl}$, blood urea: $19 \mathrm{mg} / \mathrm{dl}$, serum creatinine: $0.6 \mathrm{mg} / \mathrm{dl}$, sodium: $133 \mathrm{mE} \mathrm{q/l,} \mathrm{potassium:} 4.7 \mathrm{mEq} / \mathrm{l}$, chloride: $95 \mathrm{mE} / \mathrm{ll}$. Chest $X$-ray was normal. U rine pregnancy test was negative.

Patient then underwent an abdominopelvic ultrasound to further eval uate the mass. It was reported as a focal, fairly well defined multiloculated cystic mass $(12-14 \mathrm{~cm})$ with 
multiple thin internal septations seen at left hypochondriac region causing posteromedial displacement of spleen abutting upper pole of left kidney. Upper gastrointestinal endoscopy was done which revealed antral gastritis and extrinsic compression of stomach along the greater curvature of stomach. Patient was treated with oral pantoprazole $40 \mathrm{mg}$ once a day for the gastritis and it was decided to further evaluate the patient. To further delineate the lesion an abdominal computed tomographic (CT) scan with oral and intravenous contrast was done which showed an enlarged spleen with a $18 \times 13 \mathrm{~cm}$ fluid density lesion with multiple septa (Figs 1 and 2). The lesion showed an imperceptible wall and was seen impressing the upper pole of left kidney.

A diagnosis of lymphangioma of the spleen was made with a differential of pseudo cyst of the pancreas and it was decided to perform splenectomy as the size of the mass was large and to rule out any malignant changes.

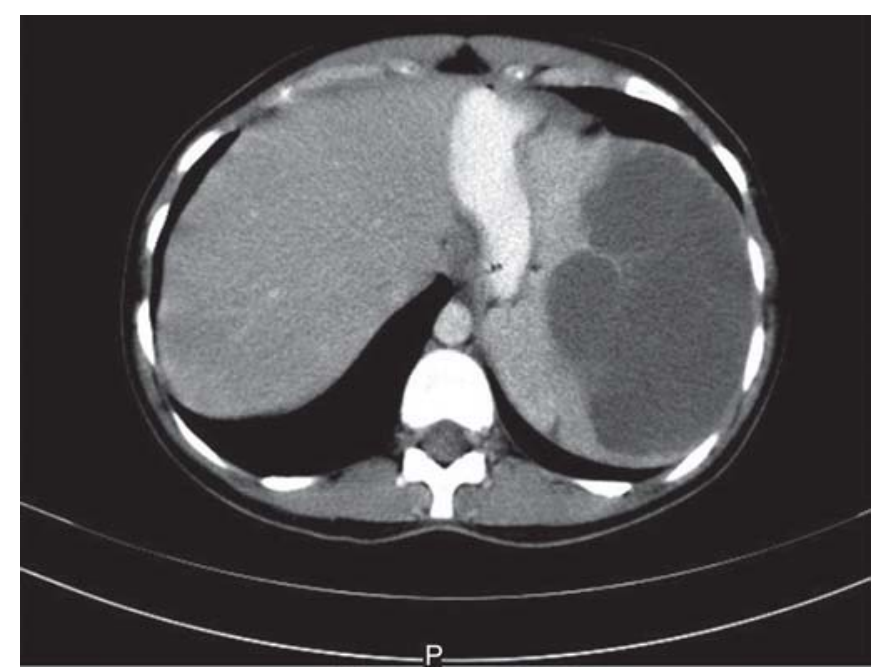

Fig. 1: CT scan of the abdomen. Axial section showing an enlarged spleen

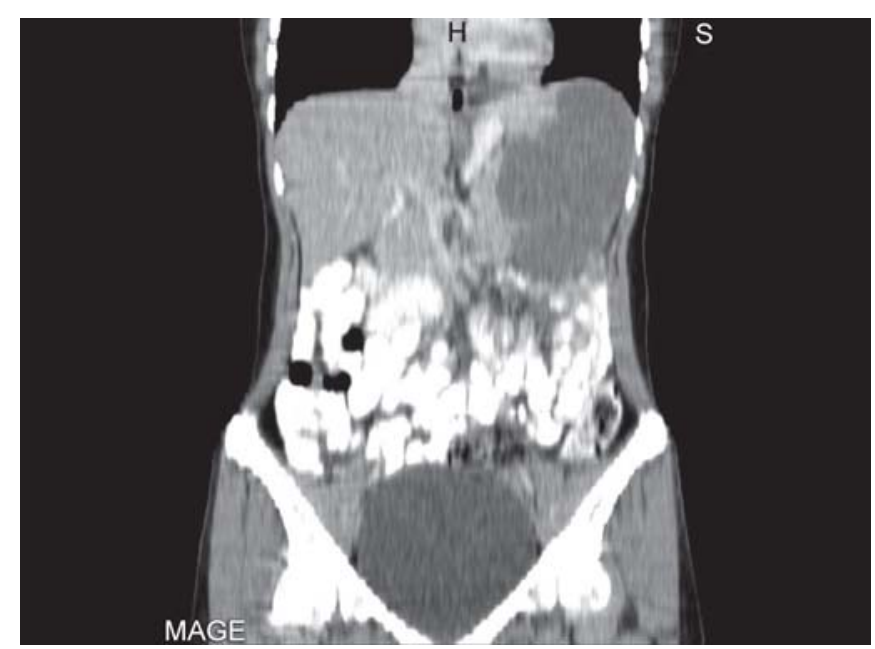

Fig. 2: CT scan of abdomen with contrast. Coronal section showing massive spleen
Patient was given pneumococcal vaccine 14 days before the planned surgery. Nasogastric tube was inserted prior to the surgery for gastric aspiration and to prevent postsplenectomy acute dilatation of stomach. Patient was given injection ceftriaxone $1 \mathrm{gm}$ chemoprophylaxis prior to the induction of surgery.

Patient underwent midline laparotomy and splenectomy was done in conventional method and the spleen measuring $19 \times 13 \times 8 \mathrm{~cm}$ weighing approximately $1,740 \mathrm{gm}$ with large multiple cysts and was sent for a histopathological evaluation (Fig. 3). Few accessory splenic masses (4 splenunculi) were also identified and removed during the surgery.

Histopathological examination on cut section revealed multiple cystic spaces filled with gelatinous material with thin rim of splenic parenchyma on the periphery. Microscopy (Fig. 4) showed multiple dilated lymphatic channels lined by endothelial cells with walls showing disorganized bundle cells and Iymphocytes with the remaining parenchyma showing congested sinuses with features consistent with lymphangioma of spleen. Since, our hospital is situated in rural part of K erala, India we were not able to do immunohistochemical study of the specimen. Patient was kept nil per oral for 2 days, and later started on oral diet. Post splenectomy platelet counts were done on day and day 14 were normal. Patient had an uneventful hospital stay and was discharged 4 days postsurgery. Skin sutures were removed on 7th day postsurgery. $0 \mathrm{n}$ subsequent reviews the patient had no further complaints.

\section{DISCUSSION}

Cystic lesions of the spleen have numbers of different classifications. ${ }^{23-26}$ Currently, the most accepted classification is whether cystic lesions can be classified as primary (true) or secondary (false), based on the presence of a cellular or brous lining. ${ }^{27,28}$ Primary cysts can be further divided into nonparasitic or parasitic (i.e. echinococcal). True nonparasitic cysts include congenital (i.e. epithelial) and neoplastic cysts (lymphangioma, metastases, hemangioma). ${ }^{24}$ False cysts may develop secondary to trauma, hemorrhage, infarction-degeneration and inammation. ${ }^{29} \mathrm{H}$ istologically, it is classified into three subtypes: Simple (capillary), cavernous and cystic. ${ }^{30}$ Cystic type is the most common. ${ }^{31}$

Lymphangiomas are benign malformations composed of endothelial-lined cysts containing lymph. ${ }^{1,32}$ The most commonly involved sites are the neck $(75 \%)$ and axilla $(20 \%))^{33}$ Lymphangioma is less commonly encountered in the mediastinum, adrenal gland, kidney, bone, omentum, gastrointestinal track, retroperitoneum, spleen, liver and pancreas. ${ }^{34-36}$ 


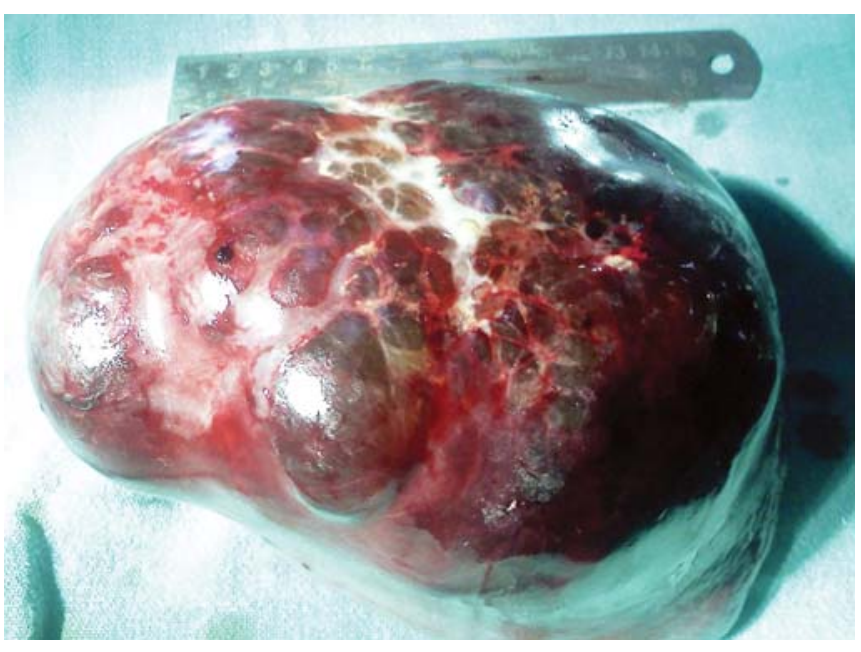

Fig. 3: Gross appearance of the spleen with a rough cystic surface

Cystic, benign, slow-growing tumors are usually seen in children, where it is discovered incidentally. ${ }^{8}$ These tumors occur more frequently in females, and 80 to $90 \%$ are detected before the end of the second year of life and rarely manifests itself after the age of 20 years. ${ }^{1,32,37}$ Lymphangioma of the spleen can involve the spleen alone either in the form of a single cyst or multiple cysts, ${ }^{38}$ or it can be a part of multivisceral involvement also known as systemic cystic angiomatosis. ${ }^{39}$

They are generally considered to be a developmental malformation in which obstruction or agenesis of lymphatic tissue results in lymphangiectasia, which is caused by a lack of normal communication of the lymphatic system. ${ }^{40-42}$ It also could be due to bleeding or inflammation of the lymphatic system which causes an obstruction leading to additional lymphangiomas. Sexual hormones can influence the growth of lymphangioma. This may explain why it is more commonly seen in females and the sudden increase in the size of lymphangioma during pregnancy. ${ }^{40,43}$

Isolated splenic Iymphangioma can present with different manifestations. ${ }^{9}$ It is asymptomatic in the majority

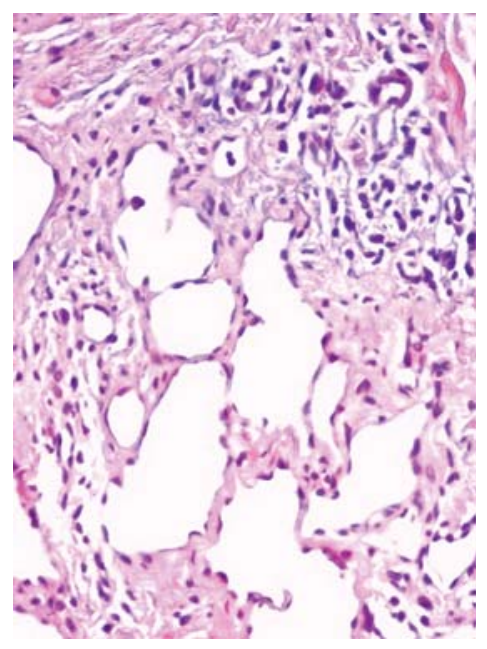

Fig. 4: Microscopic view of spleen showing dilated lymphatics of cases..$^{34,44}$ Large cystic lesions may attain sufficient size to cause significant splenomegaly and left-upper quadrant symptoms. Symptoms are usually related to the splenic size. ${ }^{45}$ The clinical manifestations of lymphangioma are left upper quadrant pain, abdominal distension, loss of appetite, nausea, vomiting and a palpable mass. These are usually nonspecific and are mostly due to compression of adjacent organs, such as stomach, diaphragm or kidney. ${ }^{46-49}$ The complications associated with more extensive or larger lymphangiomas of the spleen include bleeding, consumptive coagulopathy, hypersplenism and portal hypertension. ${ }^{2,50}$ The effect of abdominal mass produced by the lymphangioma when it exceeds 3,000 or $4,000 \mathrm{gm}$ can occasionally lead to diaphragmatic immobility and consequent atelectasis or pneumonia. ${ }^{38}$ Rarely, reversible hypertension due to renal artery compression may be seen. ${ }^{47,48}$ A cute abdominal pain, or a rapid increase in size of the cyst, may occur because of infection or rupture of a cyst. ${ }^{51-54}$

The radiologic differential diagnosis of primary vascular tumors of the spleen is often difficult to achieve, because of the frequent overlap of their features. ${ }^{55,56}$ Because the lesions are cyst-like, their appearance on ultrasound, CT and magnetic resonance imaging (M RI) is similar to and indistinguishable from one another. ${ }^{29} \mathrm{R}$ adiographic findings of the cystic form have been well described, but a radiological diagnosis of the capillary and cavernous forms is more dificult. ${ }^{57-59}$ Solitary splenic lymphangiomas are traditionally described as subcapsular, multicystic proliferations that often have identical findings. ${ }^{60}$

USG commonly shows hypoechoic spaces which may contain internal echoes. ${ }^{57,61} \mathrm{~A}$ lthough CT is nonspecific for distinguishing between many types of retroperitoneal cysts, clinical history and certain details seen at CT can assist in making the correct diagnosis. ${ }^{62} \mathrm{CT}$ scans usually demonstrate low density, ${ }^{63}$ multiple thin-walled, sharply marginated subcapsular cysts, which may contain mural calcifications, thus suggesting a diagnosis of cystic lymphangioma. $59,64,65$

On MRI, the mass is shown as multiloculated hyperintensity areas on the T2-weighted images, thus corresponding to the dilated lymphatic spaces whereas T1 imaging is only slightly increased. ${ }^{66}$ This is usually due to proteinaceous or hemorrhagic content. ${ }^{67}$ The septa are demonstrated as hypointensity bands, corresponding to an abundant amount of fibrous connective tissue. The MR findings typically correlate well with the histologic findings. ${ }^{58}$ The angiographic findings include well-defined avascular lesions of varying size scattered throughout the spleen, stretching of the intraparenchymal arterial branches, and an absence of neovascularity, arterial shunting, or 
venous pooling. A characteristic 'Swiss cheese' appearance of the spleen has been considered pathognomonic. ${ }^{3,68}$ Due to financial constraints of the patient we were unable to do a MRI of her abdomen which would have hel ped us further delineate the lesion.

Fine needle aspiration biopsy in splenic lymphangiomatosis is contraindicated because of the bleeding risk and limited amount of tissue for accurate diagnosis. ${ }^{69}$

The correct diagnosis depends on histopathologic examination after removal of the spleen. ${ }^{70}$ At gross examination, these cysts have a thick fibros wall with an internal morphology that is characterized by fibros trabeculae. Since, lymphatics are found only in the subcapsular region or in large trabeculae, these are the areas of the spleen where lymphangiomas are usually found. ${ }^{27}$ Cut section of the lymphangioma reveals a honeycombing of large and small thin-walled cysts usually containing a clear fluid composed of protein. ${ }^{55}$ A s seen at histologic analysis, capillary, cavernous, and cystic lymphangioma each consists of a single layer of flattened endotheliumlined spaces between fat, fibrotic and lymphatic structures, which are filled with eosinophilic proteinaceous material. Hyalinization and calcification of the fibrous connective tissue may be present. ${ }^{4}$

Histochemical staining of the endothelium demonstrates reactivity with CD 31, CD 34, factor V III-related antigen and keratin to varying degrees. ${ }^{71}$ Since, our hospital is situated in a rural set up in K erala, India, we do not have the required facilities required for the immunohistochemical studies. B ut the histopathological studies done on the specimen were typical of a splenic Iymphangioma with all of the characteristic features.

$M$ anagement of a splenic lymphangioma usually depends on the size. Incidental findings or small lesions do not warrant a splenectomy. L arger lesions that are symptomatic have generally been treated by a splenectomy, ${ }^{9}$ but more recently, with the advent of partial resection techniques, a partial splenectomy has al so been employed. ${ }^{72}$ For solitary single cysts, this is the preferred treatment. Leaving a splenic remnant in the diffusely involved spleen involves the risk of further growth and enlargement of the spleen, necessitating a possible second operation. A spiration has proven of little value. ${ }^{51}$

Laparoscopic splenectomy (LS) is emerging as the procedure of choice for splenic removal in patients with a normal to moderately enlarged spleen, benign tumors and hypersplenism. ${ }^{73-75}$ Successful laparoscopic complete excision of a splenic lymphangioma was first reported by K wan et al in $2001 .^{7}$

LS recommended when a splenic tumor is suspected to be either benign or borderline. ${ }^{76-79}$ However, massive splenomegaly has been considered a contraindication for
LS. ${ }^{54,80}$ During surgery, both open and laparoscopic; the search for accessory spleens is an important step. These must be removed even if they appear macroscopically normal, because they could be involved in the pathological process. $^{14,72}$

The postoperative recurrence rate and the rate of transformation into malignancy is low and the prognosis is good. ${ }^{81}$ There have been very few reports of a splenic lymphangioma developing into malignant lymphangiosarcoma. ${ }^{19}$ Complications following surgery may include peritonitis, bleeding, abscess and torsion. ${ }^{62}$

Differential diagnosis that al ways must be borne in mind include but are not limited to hydatid cysts, pancreatic pseudocysts, splenic cysts, cystic hamartomas and hemangiomas, coelomic cysts and cystic intestinal remnants. ${ }^{82}$

In a young patient with splenic lymphangioma, the diagnostic evaluation should be extended to include extrasplenic organs as it has been found that the younger the patient the more the likelihood of multiorgan involvement. $^{8}$

\section{REFERENCES}

1. Kim DH, Byun JN, Jang JY. Cystic lymphangioma involving the mesentery and the retroperitoneum: A case report. J Korean Radiol Soc 2005;52:347-50.

2. Devi N N, Pillai PG. Cystic lymphangioma of the spleen: A case report. Indian J Pathol Bacteriol 1974;17:61-62.

3. A vigad $S$, J affe $R$, Frand M, I zhak $Y$, Rotem $Y$. L ymphangiomatosis with splenic involvement. JA M A 1976;236:2315-17.

4. Chung SH, Park Y S, J O Y J, et al. A symptomatic lymphangioma involving the spleen and retroperitoneum in adults World J Gastroenterol 2009;15:5620-23.

5. A lerci M, Dore R. Computed tomography of cystic lymphangioma in a wandering spleen. Acta Radiol 1990;31:589-90.

6. A sch MJ, Cohen AH, Moore TC. Hepatic and splenic lymphangiomatosis with skel etal involvement: R eport of a case and review of the literature. Surgery 1974;76:334-39.

7. K won A-H, Inui H, Tsuji K, Takai S, Imamura A, K amiyama Y. $L$ aparoscopic splenectomy for a lymphangioma of the spleen: Report of a case. Surg Today 2001;31:258-61.

8. Wadsworth DT, Newman B, A bramson SJ, Carpenter BL, L orenzo RL. Splenic lymphangiomatosis in children. Radiology 1997;202:173-76.

9. M orgenstern L, B ello J M , Fisher BL, V erham RP. The clinical spectrum of Iymphangiomas and lymphangiomatosis of the spleen. A m Surg 1992;58:599-604.

10. Talarico C, Cerasoli V, M ancini B, et al. Lymphangiomatosis of the spleen. Report of a clinical case. A nn Ital Chir 2000;71: 599-602.

11. Spapen HD, R eynaert H, Debeuckelaere S, A chten E, Somers G. A $n$ unusual case of cystic lymphangiomatosis of the spleen. Neth J Med 1990;37:24-26.

12. Gómez A, Toscano R, Sánchez E, V ara C. Splenic lymphangiomatosis. J Chir (Paris) 1992;129:35-37.

13. Panich V. Splenic cystic lymphangiomatosis: A n unusual cause of massive splenomegaly: Report of a case. J M ed Assoc Thai 1994; 77:165-68. 
14. Barrier A, L acaine F, Callard P, Huguier M . L ymphangiomatosis of the spleen and 2 accessory spleens. Surgery 2002;131:114-16.

15. Bader TR, Ranner G, Klimpfinger M. Case report: CT appearance of capillary and cavernous lymphangiomatosis of the spleen in an adult. Clin Radiol 1998; 53:379-81.

16. Schmid C, Beham A, U ranus $S$, et al. Nonsystemic diffuse lymphangiomatosis of spleen and liver. Histopathology 1991;18: 478-80.

17. Goldberg SA. Primary splenic neoplasms. A m J Clin Pathol 1939;10:700-09.

18. Chan KW, Saw D. Distinctive, multiple lymphangiomas of spleen. J Pathol 1980;131:75-81.

19. Feigenberg $Z, W$ ysenbeek $A, A$ vidor $E$, et al. M alignant lymphangioma of the spleen. Israel J M ed Sci 1983;19:202-04.

20. Hamoudi AB, Vassy LE, Morse TS. Multiple lymphangioendothelioma of the spleen in a 13-year-old girl. A rch Pathol 1975;99:605-06.

21. Goh BK, Tan Y M, Ong HS, Chui CH, Chow PK, et al. Intraabdominal and retroperitoneal lymphangiomas in pediatric and adult patients. W orld J Surg 2005;29:837-40.

22. Allen JG, Riall TS, Cameron JL, A skin FB, RH Hruban, Campbell KA. Abdominal lymphangiomas in adults. J Gastrointest Surg 2006;10:746-51.

23. M cClure AD, Altemeier W A. Cysts of the spleen. A nn Surg 1942;116:98-102.

24. Fowler RH. Collective review: Nonparasitic benign cystic tumors of the spleen. Int A bstr Surg 1953;96:209-27.

25. Qureshi MA, Hafner CD. Clinical manifestations of splenic cysts: Study of 75 cases. A m Surg 1965;31:605-08.

26. Martin JW. Congenital splenic cysts. A m J Surg 1958;96: 302-08.

27. Pearl GS, Nasser V H. Cystic lymphangioma of the spleen. South Med J 1979;72:667-69.

28. Garvin DF, King FM . Cysts and nonlymphomatous tumor of the spleen. Pathol A nnu 1981;16:61-80.

29. Giovagnoni A, Giorgi C, Goteri G. Tumours of the spleen. Cancer I maging 2005; J uly 25;5(1):73-77.

30. Edgerton MT, Hiebert JM . V ascular and lymphatic tumors in infancy, childhood and adulthood: Challenge of diagnosis and treatment. Curr Probl Cancer 1978;2:1-44.

31. Takayama A, Nakashima O, Kobayashi K, Kojiro M. Splenic lymphangioma with papillary endothelial proliferation: A case report and review of the literature. Pathol Int 2003;53:483-88.

32. De Perrot M, Rostan 0 , M orel P, Le Coultre C. A bdominal lymphangioma in adults and children. B rJ Surg 1998;85:395-97.

33. Kosir M A, Sonnino RE, Gauderer M W L. Paediatric abdominal lymphangiomas; a plea for early recognition. J Pediatr Surg 1991;26:1309-13.

34. Chang $\mathrm{CH}$, H sieh CB, Y u JC, J an Cl. A case of lymphangioma of the spleen. J M ed Sci 2004;24:109-12.

35. Davidson AJ, Hartman DS. Lymphangioma of the retroperitoneum: CT and sonographic characteristics. Radiology 1990;175:507-10.

36. M unechika H, H onda M, K ushihashi T, K oizumi K, Gokan T. Computed tomography of retroperitoneal cystic lymphangiomas. J Comput A ssist Tomogr 1987;11:116-19.

37. Enzinger $F M, W$ eiss $S W$. Tumors of lymph vessels. In: Enzinger FM , W eiss SW (Eds). Soft tissue tumors (3rd ed). M osby $Y$ ear B ook, St L ouis 1995;687-700.

38. M orgenstern H, Rosenberg J, G eller SA. Tumors of the spleen. World J Surg 1985;9:468-76.

39. Seckler SG, Rubin H, Rabinowitz JC. Systemic cystic angiomatosis. A m J Med 1964;37:976-86.
40. Patti R, Iannitto E, Di Vita G. Splenic lymphangiomatosis showing rapid growth during lactation: A case report. World J Gastroenterol 2010;16:155-57.

41. M CL auglin CW, B eck JSP. M ultilocular cystic lymphangioma of the spleen. Arch Pathol 1933;15:655-64.

42. Bill A H, Summer DS. A unified concept of lymphangioma and cystic hygroma. Sur Gynecol Obstet 1965;120:79-86.

43. Quack L oetscher K C, J andali A R, Garzoli E, Pok J, B einder E. Axillary cavernous lymphangioma in pregnancy and puerperium. Gynecol Obstet Invest 2005;60:108-11.

44. Chan IY F, K hoo J. Retroperitoneal Iymphangioma in an adult. J HK Coll Radiol 2003;6:94-96.

45. B evilacqua $G$, Toni G, T uoni M . A case of cavernous haemangioma of the spleen. Tumori 1976;62:485-92.

46. Ross M E, Ellwood A, Y ang SS, Lucas RJ. Epidermoid splenic cysts. A rch Surg 1977;112:596-99.

47. Park JY, Song KT. Splenic cyst: A case report and review of literature. A m Surg 1971;37:544-47.

48. Economides NG, B enton BF, Fortner TM, M iles R M. Splenic pseudocysts: Report of two cases and review of the literature. A m Surg 1980;46:644-48.

49. K onen $\mathrm{O}$, R athaus $\mathrm{V}$, Dlugy $\mathrm{E}$, et al. Childhood abdominal cystic lymphangioma. Pediatr Radiol 2002;32:88-94.

50. Dietz WH J r, Stuart MJ. Splenic consumptive coagulopathy in a patient with disseminated lymphangiomatosis. J Pediatr 1977; 90:421-23.

51. M oir C, Guttman F, J equier S, Sonnino R, Y oussef S. Splenic cysts: A spiration, sclerosis or resection. J Pediatr Surg 1989;24: 646-48.

52. Katkhouda N, Hurwitz M B, Rivera RT, et al. Laparoscopic splenectomy: O utcome and efcacy in 103 consecutive patients. A nn Surg 1998;228:568-78.

53. Hashizume $M$, Tanoue $K$, M orita M, Ohta M, Tomikawa M, Sugimachi K. Laparoscopic gastric devascularization and splenectomy for sclerotherapy-resistant esophagogastric varice with hypersplenism. J A m Coll Surg 1998;187:263-70.

54. Targarona EM, Espert JJ, B alague C, Piulachs J, A rtigas V, Trias $M$. Splenomegaly should not be considered a contraindication for laparoscopic splenectomy. A nn Surg 1998;228:35-39.

55. Ros PR, M oser RP J r, Dachman A H, M urari PJ , O Imsted W W. Hemangioma of the spleen: Radiologic-pathologic correlation in ten cases. Radiology 1987;162:73-77.

56. Suster S. Epithelioid and spindle-cell hemangioendothelioma of the spleen. A m J Surg Pathol 1992;16:785-92.

57. Kawashima A, Fishman EK. Benign and malignant splenic lesions. In: Gore RM, L evine M S, L aufer I (Eds). Textbook of gastrointestinal radiology. Philadel phia: Saunders 1994:2251-87.

58. Pistoia F, Markowitz SK. Splenic lymphangiomatosis: CT diagnosis. AJR 1988;50:121-22.

59. Ito K, M urata T, Nakanishi T. Cystic Iymphangioma of the spleen: M R findings with pathological correlation. A bdom I mag 1995;20:82-84.

60. A rber DA, Strickler JG, W eiss L M. Splenic mesothelial cysts mimicking Lymphangiomas. A m J Surg Pathol 1997;21: 334-38.

61. K omatsuda T, I shida H, K onno K, Hamashima $Y$, Naganuma $H$, Sato $M$, et al. Splenic lymphangioma: US and CT diagnosis and clinical manifestations. A bdom I mag 1999;24:414-17.

62. $Y$ ang $D M$, J ung $D H, K i m ~ H, K$ ang J H, K im SH, K im JH, et al. Retroperitoneal cystic masses: CT, clinical, and pathologic findings and literature review. Radiographics 2004;24: 1353-65. 
63. Kaza RK, Azar S, Francis IR, et al. Primary and secondary neoplasms of the spleen. Cancer I mag 2010;10:173-82.

64. A bbottRM , Levy AD, A guilera NS, GorospeL, Thompson WM. From the archives of the AFIP: Primary vascular neoplasms of the spleen: Radiologic-pathologic correlation. Radiographics 2004;24:1137-63.

65. Rolfes RJ, Ros PR. The spleen: A n integrated imaging approach. Crit Rev Diagn Imag 1990;30:41-83.

66. Solomou EG, Patriarheas GV, M padra FA, K aramouzis M V, DimopoulosI. A symptomatic adult cystic lymphangioma of the spleen: Case report and review of the literature. M agn Reson Imaging 2003;21:81-84.

67. Urrutia M, M ergo PJ, Ros LH, Torres GM, Ros PR. Cystic masses of the spleen: Radiologic-pathologic correlation. Radiographics 1996;16:107-29.

68. Tuttle RJ, M inielly JA. Splenic cystic Iymphangiomatosis. Radiology 1978;126:47-48.

69. Alkofer B, Lepennec V, Chiche L. Splenic cysts and tumors: Diagnosis and management. J Chir (Paris) 2005;142:6-13.

70. A nadol AZ, Oguz M, Bayramoglu N, Edali MN. Cystic lymphangioma of the spleen mimicking hydatid disease. J Clin Gastroenterol 1998;26:309-11.

71. Qutub W, L ewis K, Gonzalez R, Q uaife R, Russ P, M cC arter M. Lymphangiomatosis masquerading as metastatic melanoma. A m Surg 2006;72:367-70.

72. K han $A H, B$ ensoussan $A L$, Ouimet A, B lanchard $H$, Grignon $A$, $N$ doye $M$. Partial splenectomy for benign cystic lesions of the spleen. J Pediatr Surg 1986;21:749-52.

73. SchlinkertRT, Teotia SS. L aparoscopic splenectomy. A rch Surg 1999;134:99-103.

74. Caprotti R, Porta G, Franciosi C, Codecasa G, Romano F, M usco $F$, et al. Laparoscopic splenectomy for hematological disorders. Our experience in adult and pediatric patients. Int Surg 1998;83:303-07.
75. K lingler PJ, Tsiotos G G, Glaser KS, Hinder RA . L aparoscopic splenectomy: Evolution and current status. Surg Laparosc Endosc 1998;9:1-8.

76. M aluenda $F G, B$ urdiles $P P, B$ raghetto $I M, C$ sendes $A J$. Hematologic diseases laparoscopic splenectomy. Rev M éd Chile 2004;132:189-94.

77. Sellers GJ, Starker PM . Laparoscopic treatment of to benign splenic cyst. Surg Endosc 1997;11:766-68.

78. Fahel E, A maral PCG, Filho EM A. Videolaparoscopic approach of the splenic cyst: A case report. J Soc Laparoendosc Surg 2000;4:23-26.

79. Comitalo JB. Laparoscopic treatment of splenic cysts. J Soc L aparoendosc Surg 2001;5:313-36.

80. M aurus CF, Schäfer M, M üller MK, Clavien PA, W eber M . $L$ aparoscopic versus open splenectomy for nontraumatic diseases. World J Surg 2008;32:2444-49.

81. W itzel K, K ronsbein H, Pleser M, Hunfeld H, Rumpf K D. Intraabdominal cystic lymphangioma in childhood. R eport of 2 cases. Zentralbl Chir 1999;124:159-62.

82. Ferrozzi F, Bova D, Draghi F, Garlaschi G. CT findings in primary vascular tumors of the spleen. AJR 1996;166:1097-101.

\section{ABOUT THE AUTHORS}

\section{Basil George Verghese (Corresponding Author)}

Department of M edicine, St J ohn's H ospital, K attappana, K erala, India e-mail: drbasilgeorge@gmail.com

\section{Sanjana Kalvehalli Kashinath}

Department of Pediatrics, CG Hospital, D avangere, K arnataka, India

\section{R Ravi Kanth}

Department of Surgery, CG Hospital, Davangere, K arnataka, India 